Arq. Bras. Med. Vet. Zootec., v.62, n.1, p.178-183, 2010

\title{
Determinação da energia metabolizável de alimentos para codornas japonesas em postura
}

\author{
[Metabolizable energy of different feedstuffs tested in female Japanese quails]
}

A.M.A. Moura ${ }^{1}$, J.B. Fonseca ${ }^{2}$, F.N. Takata ${ }^{3}$, C.B.V. Rabello ${ }^{4}$, C.T. Lombardi ${ }^{2}$

\author{
${ }^{1}$ Centro de Pesquisas Aggeu Magalhães - FIOCRUZ \\ Av. Moraes Rego, s/n. \\ 50670-420 - Recife, PE \\ ${ }^{2}$ Universidade Estadual do Norte Fluminense - Campos dos Goytacazes, RJ \\ ${ }^{3}$ Médica veterinária autônoma - Recife, PE \\ ${ }^{4}$ Universidade Federal Rural de Pernambuco - Recife, PE
}

\begin{abstract}
RESUMO
Foram determinados os valores de energia metabolizável aparente (EMA), de energia metabolizável aparente corrigida por retenção de nitrogênio $\left(\mathrm{EMA}_{\mathrm{n}}\right)$ e do coeficiente de metabolização aparente da energia bruta (CMAEB\%) do milho, sorgo, farelo de soja, farelo de glúten de milho e óleo de soja refinado. Foram utilizadas 240 codornas japonesas (Coturnix japonica), fêmeas com idade inicial de 60 dias, em delineamento experimental inteiramente ao caso, com seis tratamentos, cinco repetições e oito codornas por unidade experimental. Os tratamentos consistiram de cinco rações experimentais e uma ração referência. Cada ração experimental foi constituída, na base da matéria natural, por $70 \%$ da ração referência e $30 \%$ do ingrediente a ser testado, com exceção da ração para determinação da $\mathrm{EMA}_{n}$ do óleo de soja, com $10 \%$ de inclusão e $90 \%$ da ração referência. $\mathrm{O}$ experimento foi realizado em gaiolas distribuídas em baterias metálicas. Os valores de EMA, EMAn (em kcal/kg de matéria natural) e do CMAEB (\%) do milho moído, sorgo, farelo de soja, farelo de glúten de milho e óleo de soja refinado foram, respectivamente: 3.572 e $3.612 \mathrm{kcal} / \mathrm{kg}$ e $92,6 \% ; 3.108$ e $3.149 \mathrm{kcal} / \mathrm{kg}$ e $80,9 \% ; 2.633$ e $2.676 \mathrm{kcal} / \mathrm{kg}$ e $65,3 \% ; 4.043$ e $4.096 \mathrm{kcal} / \mathrm{kg}$ e $75,0 \% ; 9.335$ e $9.379 \mathrm{kcal} / \mathrm{kg}$ e $98,8 \%$. Os valores de EMA descritos para outras espécies de aves são discrepantes dos obtidos no presente estudo, não sendo recomendado seu uso em formulação de rações para codornas japonesas em postura.
\end{abstract}

Palavras-chave: codorna japonesa, ensaio de metabolismo, sorgo, alimento alternativo

\begin{abstract}
The values of the apparent metabolizable energy (AME), the apparent metabolizable energy corrected for nitrogen retention $\left(A M E_{n}\right)$, and the apparent metabolization coefficient of crude energy (AMCCE) were determined in corn, sorghum, soybean meal, corn gluten meal, and refined soybean oil. Two-hundred and forty six-day-old female Japanese quails (Coturnix japonica) were used in a completely randomized design, with five replicates and eight quails per experimental unit. The treatments consisted of six experimental diets and one reference diet. Each experimental diet was constituted, as fed basis, for $70 \%$ of the reference ration and $30 \%$ of food that would be tested, except the ration that contained refined soybean oil that was tested, as fed basis, with $10 \%$ of addition and $90 \%$ of the reference ration. The biological assay was carried out in wired floor cages distributed in iron batteries. The respective values of AME, AMEn (kcal/kg of natural matter basis), and AMCCE (\%) of ground corn, sorghum, soybean meal, corn gluten meal, and refined soybean oil were respectively: 3,572, 3,612kcal/kg, and $92.6 \% ; 3,108,3,149 \mathrm{kcal} / \mathrm{kg}$, and $80.9 \% ; 2,633,2,676 \mathrm{kcal} / \mathrm{kg}$, and $65.3 \% ; 4,043,4,096 \mathrm{kcal} / \mathrm{kg}$, and 75.0\%; and 9,335, 9,379kcal/kg, and 98.8\%. The values of AME described for other birds species were different from those obtained in this study and are not recommended to be used in ration composition for Japanese quails.
\end{abstract}

Keywords: Japanese quail, digestibility assay, alternative food

Recebido em 7 de julho de 2009

Aceito em 2 de fevereiro de 2010

E-mail: antoniol@cpqam.fiocruz.br 


\section{INTRODUÇÃO}

A coturnicultura é uma atividade avícola de cadeia produtiva consolidada, que produz proteína de origem animal de alta qualidade e de custo relativamente baixo. A codorna japonesa (Coturnix japonica; Temminck e Schlegel, 1849) tem passado por um processo constante de melhoramento genético a fim de selecionar linhagens com elevado potencial produtivo. $\mathrm{O}$ atendimento de suas exigências nutricionais, como a de energia metabolizável, é imprescindível para que se alcance a produção esperada.

A energia metabolizável é uma propriedade nutricional estratégica em sistemas de criações em que se utiliza alimentação à vontade, pois o consumo alimentar é regulado principalmente pela densidade calórica da ração e que pode determinar a eficiência produtiva e econômica da atividade. Normalmente as exigências de proteína bruta, aminoácidos e de outros nutrientes são expressas em função dos níveis de energia metabolizável da ração (Silva et al., 2003).

O refinamento na formulação de rações para aves é prática contínua dos nutricionistas de animais que visam melhorar a economicidade da cadeia produtiva, adequando o perfil bromatológico dos ingredientes às exigências nutricionais de cada categoria zootécnica. O conhecimento do valor energético dos alimentos está incluído neste conceito, pois, segundo Sakomura e Rostagno (2007), é de fundamental importância nutricional e econômica, uma vez que representa grande parte dos custos de formulação. No entanto, a efetividade do método de formulação depende da precisão com que o valor energético dos alimentos foi determinado (Matterson et al., 1965).

Muitos fatores podem interferir nos valores de energia metabolizável dos alimentos, como, por exemplo, a espécie (Silva et al., 2003, 2008), idade (Freitas et al., 2005; Santos et al., 2006), sexo, protocolo experimental, composição química, granulometria, processamento da ração (Penz Jr. et al., 1999), taxa de passagem no trato digestório, quantidade, frequência e tempo de fornecimento do alimento, além de variações individuais (Murakami e Furlan, 2002).

Apesar de ainda não haver uma tabela de composição de alimentos específica para codornas, como as encontradas para frangos de corte e poedeiras, pesquisas vêm sendo realizadas não só para atualizar os valores nutricionais dos alimentos comumente usados nas formulações de rações, como também para conhecer $\mathrm{o}$ valor nutricional de alimentos alternativos (Furlan et al., 1998; Silva et al., 2003, 2008; Freitas et al., 2005; Santos et al., 2006; Gomes et al., 2007; Oliveira et al., 2007).

O objetivo deste trabalho foi determinar os valores de energia metabolizável aparente e energia metabolizável aparente corrigida por retenção de nitrogênio do milho, sorgo, farelo de soja, farelo de glúten de milho 60 e do óleo de soja refinado em codornas japonesas em postura.

\section{MATERIAL E MÉTODOS}

O experimento foi realizado com 240 codornas japonesas fêmeas, de linhagem comercial, com 60 dias de idade, selecionadas pelo peso corporal e pela taxa de postura, e alojadas em gaiolas metálicas $(33 \times 25 \times 20 \mathrm{~cm})$, sobrepostas em cinco andares com seis gaiolas. Cada gaiola foi equipada com comedouro e bebedouro tipo calha e bandeja para coleta das excretas, devidamente forrada com plástico branco.

As aves, alojadas na densidade de oito aves/gaiola, foram mantidas sob um programa de luz contínuo de 24 horas/dia, a fim de estimular o consumo da dieta. As lâmpadas fluorescentes foram distribuídas dentro da sala experimental de forma que todas as gaiolas recebessem iluminação equivalente, sem sombreamento dos comedouros. As codornas foram distribuídas em delineamento inteiramente ao acaso, com seis tratamentos, cinco repetições e oito aves por unidade experimental. Os tratamentos foram constituídos por seis dietas, cinco experimentais e uma dieta referência (Tab. 1). Os ingredientes testados foram: milho grão, sorgo granífero de baixo tanino (cultivar IPA 1011), farelo de soja, farelo de glúten de milho 60 e óleo de soja refinado. 
Tabela 1. Composição percentual e valor nutricional calculado da dieta-referência usada para codornas japonesas

\begin{tabular}{|c|c|}
\hline Alimentos & $(\%)$ \\
\hline Milho & 56,047 \\
\hline Farelo de soja & 33,826 \\
\hline Fosfato bicálcico & 1,320 \\
\hline Calcário & 5,182 \\
\hline Óleo de soja & 2,713 \\
\hline Suplemento vitamínico e mineral ${ }^{1}$ & 0,500 \\
\hline Cloreto de sódio & 0,333 \\
\hline DL-Metionina & 0,070 \\
\hline Antioxidante $^{2}$ & 0,010 \\
\hline \multicolumn{2}{|c|}{ Valor nutricional calculado } \\
\hline Energia metabolizável (kcal/kg) & 2.900 \\
\hline Proteína bruta, $\%$ & 20,00 \\
\hline Metionina + Cistina total, $\%$ & 0,82 \\
\hline Metionina total,\% & 0,50 \\
\hline Lisina total, $\%$ & 1,30 \\
\hline Treonina total, $\%$ & 0,76 \\
\hline Cálcio,\% & 0,80 \\
\hline Fósforo disponível,\% & 0,30 \\
\hline Sódio, $\%$ & 0,15 \\
\hline
\end{tabular}

${ }^{\top}$ Puramix Codorna (quantidade por $\mathrm{kg}$ )= metionina: $218000 \mathrm{mg}$; cianocobalamina: $10000 \mathrm{mcg}$; ácido fólico: $400 \mathrm{mg}$; pantotenato de cálcio: $3000 \mathrm{mg}$; biotina: $10 \mathrm{mg}$; colina: $126.000 \mathrm{mg}$; niacina: $7000 \mathrm{mg}$; piridoxina: $800 \mathrm{mg}$; tiamina: 800mg; riboflavina: $1200 \mathrm{mg}$; menadiona: 500mg; vit.A: 2000000UI; vit.D3: 50000UI; vit.E: 10000UI; cobre: 2000mg; ferro: 16000mg; iodo: 200mg; manganês: $18000 \mathrm{mg}$; zinco: $14000 \mathrm{mg}$; selênio: $10000 \mathrm{mcg}$. ${ }^{2}$ Butil-hidroxitolueno (BHT).

Cada dieta experimental foi constituída, na base da matéria natural, por $70 \%$ da dieta-referência e $30 \%$ do ingrediente a ser testado, à exceção da dieta contendo óleo de soja refinado, que foi testado, na base da matéria natural, com $10 \%$ de inclusão e $90 \%$ da dieta-referência. O período experimental foi de oito dias, sendo quatro dias de adaptação e quatro de coletas de excretas. O fornecimento da dieta foi ad libitum, duas vezes ao dia, porém, na proporção de $30 \mathrm{~g} / \mathrm{ave} / \mathrm{dia}$ para evitar desperdício nos comedouros. No final do período de coleta, as sobras de cada repetição foram pesadas para determinação do consumo.

Foi utilizado o método tradicional de coleta total de excretas, usando o óxido férrico (1\%) como marcador fecal para indicar o início e o término do período de coletas. As excretas foram coletadas duas vezes ao dia (manhã e tarde). Após cada coleta, as excretas foram cuidadosamente separadas de contaminantes macroscópicos, como penas e grânulos da dieta, pesadas, acondicionadas em sacos plásticos identificados de acordo com a parcela e armazenadas em freezer $\left(-20^{\circ} \mathrm{C}\right)$. Ao término do período de coletas, as excretas foram descongeladas, homogeneizadas e pesadas, retirando-se $450 \mathrm{~g}$ de amostra por parcela. As amostras foram pré-secadas em estufa de ventilação forçada por 72 horas a $55^{\circ} \mathrm{C}$ e, posteriormente, moídas e acondicionadas em embalagens plásticas para as análises.

As análises bromatológicas das amostras dos ingredientes e das excretas foram realizadas no Laboratório de Zootecnia e Nutrição Animal da Universidade Estadual do Norte Fluminense, onde foram determinadas a matéria seca, nitrogênio total e energia bruta, de acordo com as metodologias descritas por Silva e Queiroz (2002). A energia bruta foi determinada em bomba calorimétrica adiabática PARR (modelo 1271) e o nitrogênio em aparelho semimicro Kjeldahl.

A partir desses dados, foram determinados os valores de energia metabolizável aparente (EMA), energia metabolizável aparente corrigida para retenção de nitrogênio (EMAn) e do coeficiente de metabolização aparente da energia bruta (CMAEB), utilizando-se as equações descritas por Matterson et al. (1965). 
Os valores de CMAEB obtidos de cada tratamento foram comparados por meio do teste SNK com probabilidade a 0,05 de significância, utilizando o programa estatístico SAEG, versão 9.1 (Sistema..., 2007).

\section{RESULTADOS E DISCUSSÃO}

Temperatura e umidade foram registradas diariamente em três horários $(8 \mathrm{~h}, 13 \mathrm{~h}$ e $17 \mathrm{~h})$. As temperaturas média, máxima e mínima foram $26,6,28,2$ e $25,4^{\circ} \mathrm{C}$, respectivamente, e a umidade relativa do ar média foi de $78 \%$ durante o período experimental.

Os valores médios de matéria seca, de proteína bruta e energia bruta do milho, sorgo, farelo de soja, farelo de glúten de milho 60 e óleo de soja encontram-se na Tab. 2.

Tabela 2. Valores médios de matéria seca (MS), proteína bruta $(\mathrm{PB})$ e energia bruta (EB) dos ingredientes testados nas dietas experimentais usadas para codornas

\begin{tabular}{lccc}
\hline Ingrediente & MS $(\%)$ & PB $(\%)^{1}$ & EB $(\mathrm{kcal} / \mathrm{kg})^{1}$ \\
\hline Milho & $87,17 \pm 1,78$ & $8,38 \pm 0,70$ & $3.901 \pm 49,4$ \\
Sorgo & $86,34 \pm 0,93$ & $10,99 \pm 0,49$ & $3.893 \pm 37,5$ \\
Farelo de soja & $86,64 \pm 1,73$ & $45,00 \pm 0,68$ & $4.099 \pm 53,2$ \\
Farelo de glúten de milho 60 & $91,96 \pm 0,79$ & $65,71 \pm 0,39$ & $5.460 \pm 56,3$ \\
Óleo de soja refinado & $99,65 \pm 0,57$ & -- & $9.297 \pm 70,3$ \\
\hline
\end{tabular}

${ }^{1}$ valores expressos na matéria natural.

Os valores médios e os desvios-padrão de energia metabolizável aparente e energia metabolizável aparente corrigida por retenção de nitrogênio, expressos em kcal por kg de matéria natural, assim como o resumo da análise de variância do coeficiente de metabolização aparente da energia bruta (\%), são apresentados na Tab. 3.

Tabela 3. Valores médios e desvios-padrão de energia metabolizável aparente (EMA), energia metabolizável aparente corrigida por retenção de nitrogênio (EMAn) e coeficiente de metabolização aparente da energia bruta (CMAEB) dos ingredientes testados em codornas japonesas

\begin{tabular}{lccc}
\hline Ingrediente & EMA & EMAn & CMAEB $^{1}$ \\
\hline & \multicolumn{1}{c}{ kcal por kg de matéria natural } & $\%$ \\
\hline Milho & $3.572 \pm 104,9$ & $3.612 \pm 92,80$ & $92,59 \pm 7,25 \mathrm{a}$ \\
Sorgo & $3.108 \pm 256,7$ & $3.149 \pm 262,8$ & $80,89 \pm 8,53 \mathrm{~b}$ \\
Farelo de soja & $2.637 \pm 121,2$ & $2.676 \pm 122,5$ & $65,29 \pm 3,56 \mathrm{c}$ \\
Farelo de glúten de milho & $4.043 \pm 126,6$ & $4.096 \pm 136,0$ & $75,02 \pm 16,7 \mathrm{~b}$ \\
Óleo de soja refinado & $9.335 \pm 248,5$ & $9.379 \pm 397,1$ & $98,85 \pm 1,76 \mathrm{a}$ \\
\hline C.V. & & & $5,66 \%$ \\
\hline
\end{tabular}

${ }^{\mathrm{T}}$ Médias seguidas por letras distintas na coluna diferem entre si pelo teste de SNK a 5\% de probabilidade.

Os valores de EMA e EMAn dos ingredientes testados foram mais altos que os descritos nas tabelas brasileiras para aves e suínos (Rostagno et al., 2005). O mesmo padrão de resposta foi observado por Gomes et al. (2007), em que EMAn do sorgo e de duas fontes de farelo de soja determinadas com codornas em postura foram mais elevadas que as citadas por Rostagno et al. (2005). Essas informações evidenciam maior capacidade de metabolização da energia contida nos alimentos pelas codornas, comparadas a outras espécies de aves, como frangos de corte e poedeiras.
Silva et al. (2008), ao determinarem a energia metabolizável aparente de alguns alimentos alternativos para pintos, galos e codornas, verificaram maior valor de EMA para o farelo de castanha de caju para as codornas e valores similares aos dos galos com as demais fontes alimentares. O valor de EMAn foi semelhante aos 2.592 e $2.651 \mathrm{kcal} / \mathrm{kg}$ do farelo de soja, determinados por Furlan et al. (1998) e Oliveira et al. (2007), respectivamente, e aos $3.992 \mathrm{kcal} / \mathrm{kg}$ do farelo de glúten 60 relatados por Silva et al.(2003). Para os valores de EMAn do milho, sorgo e óleo de soja refinado, não se observaram 
semelhanças com as informações descritas na literatura citada. É importante considerar as particularidades intrínsecas a cada experimento que podem ter gerado resultados semelhantes ou divergentes entre o presente estudo e os citados na literatura consultada. A composição de um resultado experimental é multifatorial e dificilmente serão repetidas as mesmas condições em diferentes estudos.

As diferenças entre matéria-prima utilizada na formulação das dietas experimentais também devem ser consideradas, pois a origem do cultivar, o armazenamento, a granulometria, a composição bromatológica, dentre outras, influenciam diretamente a eficiência de utilização dos nutrientes pelas aves.

As diferenças entre os resultados determinados neste estudo e os dos referenciados são mais importantes sob a ótica econômica do que acadêmica. Por exemplo, ao comparar percentualmente a diferença entre o valor de $9.379 \mathrm{kcal} / \mathrm{kg}$ de EMAn do óleo de soja, determinado no presente estudo, com os $8.777 \mathrm{kcal} / \mathrm{kg}$ descritos por Gomes et al. (2007), a diferença é de apenas 6,4\%. Essa diferença aparentemente pequena representa $602 \mathrm{kcal} / \mathrm{kg}$ de EMAn entre os dois estudos.

Houve efeito significativo $(\mathrm{P}<0,05)$ da fonte alimentar sobre o coeficiente de metabolização aparente da energia bruta. O óleo de soja refinado $(95,7 \%)$ e o milho $(92,6 \%)$ apresentaram maior valor de CMAEB, seguidos pelo sorgo $(80,9 \%)$ e o farelo de glúten de milho $60(75,0 \%)$. O menor valor foi obtido pelo farelo de soja $(65,3 \%)$.

O valor de CMAEB do milho foi mais alto que os $89,0 \%$ e $74,6 \%$ relatados por Furlan et al. (1998) e Silva et al. (2003), respectivamente. Para o farelo de soja, sorgo e óleo de soja refinado, os valores do CMAEB foram semelhantes aos determinados por Gomes et al. (2007) que encontraram 62,9\%, 86,6\% e 93,0\%, respectivamente. Furlan et al. (1998) também verificaram valor semelhante de CMAEB para o farelo de soja (63,3\%), enquanto Silva et al. (2003) obtiveram valor mais baixo $(50,1 \%)$. O CMAEB do farelo de glúten 60 foi semelhante aos $69,4 \%$ descrito por Silva et al. (2003).
O CMAEB é influenciado por inúmeros fatores, dentre eles a qualidade da fonte alimentar. Isso porque a eficiência de metabolização da energia (k) varia com a composição da dieta, porque os nutrientes (carboidratos, proteínas e lipídios) não são utilizados com a mesma eficiência pelas aves (Sakomura e Rostagno, 2007).

Segundo De Groote (1974), a eficiência de utilização da energia das proteínas, lipídios e carboidratos pelas aves é de $60 \%, 90 \%$ e $75 \%$, respectivamente, e a relação amido/fibra bruta também é determinante para a eficiência de metabolização da energia dos grãos, porque o amido tem eficiência em torno de $80 \%$, enquanto a fibra bruta, apenas $50 \%$.

Isso explica o menor valor de CMAEB do farelo de soja em relação ao milho e ao sorgo. Segundo Rostagno et al. (2005), os percentuais de amido e de fibra bruta no milho são, respectivamente, 62,5 e $1,7 \%$, e no sorgo baixo tanino, 60,8 e $2,3 \%$. O farelo de soja apresenta reduzido teor de amido, $12,4 \%$, e elevado de fibra bruta, $5,4 \%$, o que reduz sua eficiência de metabolização da energia pelas codornas.

O farelo de glúten de milho 60 é um subproduto do processamento do milho e por isso apresenta baixo teor de amido, porém é fonte proteica de alta digestibilidade, o que justifica seu elevado valor de CMAEB. O óleo de soja refinado, por ser um lipídio, apresenta maior eficiência de utilização da energia metabolizável em relação às fontes proteicas e de carboidratos.

Estes resultados estão coerentes com os obtidos por Gomes et al. (2007), Silva et al. (2003) e Furlan et al. (1998), que observaram maior CMAEB para as fontes alimentares de acordo com a composição bromatológica, segundo o grau de eficiência descrita por De Groote (1974).

Deve-se considerar as particularidades de cada espécie, dentro de cada categoria e aptidão zootécnica, e não medir esforços para a realização de mais estudos a fim de se obter maior número de dados para melhor adequação das dietas às exigências das codornas. Pelo exposto, não é recomendável a utilização de informações das tabelas para frangos de corte e poedeiras para compor rações para codornas japonesas. 


\section{CONCLUSÕES}

Os valores de energia metabolizável aparente e energia metabolizável aparente corrigida pelo balanço de nitrogênio, para codornas japonesas em postura, do milho, sorgo, farelo de soja, farelo de glúten de milho e óleo de soja refinado, são: 3.572 e $3.612 ; 3.108$ e $3.149 ; 2.633$ e 2.676 ; 4.043 e $4.096 ; 9.335$ e $9.379 \mathrm{kcal} / \mathrm{kg}$ de matéria natural, respectivamente. $\mathrm{O}$ coeficiente de metabolização aparente da energia bruta foi de $92,6 \%$ para o milho, $80,9 \%$ para o sorgo baixo tanino, 65,3 para o farelo de soja, $75,0 \%$ para o farelo de glúten 60 e 98,9\% para o óleo de soja refinado. Os valores de energia metabolizável aparente corrigida pelo balanço de nitrogênio do milho, sorgo, farelo de soja, farelo de glúten de milho e óleo de soja refinado para codornas japonesas são diferentes dos descritos para outras espécies de aves. O uso de dados de energia metabolizável aparente descritos para frangos de corte de galinhas poedeiras não é recomendado para codornas japonesas em postura.

\section{REFERÊNCIAS BIBLIOGRÁFICAS}

DE GROOTE, G. Utilization of metabolizable energy. In: MORRIS, T.R.; FREEMAN, B.M. (Ed.). Energy requirements of poultry. Edinburgh: British Poultry Science, 1974. p.113133.

FREITAS, E.R.; SAKOMURA, N.K.; NEME, R. et al. Efeito do processamento da soja integral sobre a energia metabolizável e a digestibilidade dos aminoácidos para aves. Rev. Bras. Zootec., v.34, p.1948-1949, 2005.

FURLAN, A.C.; OLIVEIRA, A.M.; MURAKAMI, A.E. et al. Valores energéticos de alguns alimentos determinados com codornas Japonesas (Coturnix coturnix japonica). Rev. Bras. Zootec., v.27, p.1147-1150, 1998.

GOMES, F.A.; FASSANI, E.J.; RODRIGUES, P.B. et al. Valores energéticos de alguns alimentos utilizados em rações para codornas japonesas. Rev. Bras. Zootec., v.36, p.396-402, 2007.

MATTERSON, L.B.; POTTER, L.M.; STUTZ, M.W. et al. The metabolizable energy of feed ingredients for chickens. Agric. Exp. Sta. Univ. Conn. Res. Rep., n.7, p.3-11, 1965.
MURAKAMI, A.E.; FURLAN, A.C. Pesquisa na nutrição e alimentação de codornas em postura no Brasil. In: SIMPÓSIO INTERNACIONAL DE COTURNICULTURA, 1., 2002, Lavras. Anais... Lavras: UFLA, 2002. p.113-120.

OLIVEIRA, N.T.E.; FONSECA, J.B.; SOARES, R.T.R.N. et al. Determinação da energia metabolizável de diferentes alimentos testados em codornas japonesas fêmeas. Arq. Bras. Med. Vet. Zootec., v.59, p.210-217, 2007.

PENZ Jr., A.M.; KESSLER, A.M.; BRUGALLI, I. Novos conceitos de energia para aves. In: SIMPÓSIO INTERNACIONAL SOBRE NUTRIÇÃO DE AVES, 1999, Campinas. Anais... Campinas: FACTA, 1999. p.1-24.

ROSTAGNO, H.S.; ALBINO, L.F.T.; DONZELE, J.L. et al. Tabelas brasileiras para aves e suínos: Composição de alimentos $\mathrm{e}$ exigências nutricionais. Viçosa: UFV, 2005. $141 \mathrm{p}$.

SAKOMURA, N.K.; ROSTAGNO, H.S. Métodos de pesquisa em nutrição de monogástricos. Jaboticabal: FUNEP, 2007. 283p.

SANTOS, A.L.S.; GOMES, A.V.C.; PESSÔA, M.F. et al. Composição química e valores energéticos de fontes proteicas em codornas de corte em diferentes idades. Cienc. Rural, v.36, p.930-935, 2006.

SILVA, D.J.; QUEIROZ, A.C. Análise de alimentos: métodos químicos e biológicos. 3.ed. Viçosa: UFV, 2002. 235p.

SILVA, J.H.V.; SILVA, M.B.; SILVA, E.L. et al. Energia metabolizável de alimentos determinada com codornas japonesas (Coturnix coturnix japonica). Rev. Bras. Zootec., v.32, supl.2, p.1912-1918, 2003.

SILVA, R.B.; FREITAS, E.R.; FUENTES, M.F.F. Composição química e valores de energia metabolizável de subprodutos agroindustriais determinados com diferentes aves. Acta Sci. Anim. Sci., v.30, p.269-275, 2008.

SISTEMA de análises estatísticas - SAEG, versão 9.1. Viçosa: UFV, 2007. 